\title{
АНАЛИЗ МИРОВОГО ОПЫТА ИСПОЛЬЗОВАНИЯ ИПОТЕЧНЫХ ОБЛИГАЦИЙ
}

\author{
(c) 2020 Цапикова Елизавета Алексеевна \\ студент специалитета кафедры «Строительство уникальных зданий и сооружений» \\ Сибирский федеральный университет, Россия, Красноярск \\ E-mail: capikoval9@gmail.com \\ (c) 2020 Катцина Эмма Вадимовна \\ студент специалитета кафедры «Строительство уникальных зданий и сооружений» \\ Сибирский федеральный университет, Россия, Красноярск \\ E-mail: kattsinaemma@mail.ru \\ (c) 2020 Лопатина Полина Максимовна \\ студент специалитета кафедры «Строительство уникальных зданий и сооружений» \\ Сибирский федеральный университет, Россия, Красноярск \\ E-mail: polinalopatina4@mail.ru \\ (c) 2020 Полуштайцева Валерия Владимировна \\ студент кафедры инженерных систем зданий и сооружений \\ Сибирский федеральный университет, Россия, Красноярск \\ E-mail: polushtaytseva@bk.ru \\ ( 2020 Рослякова Мария Александровна \\ студент специалитета кафедры «Строительство уникальных зданий и сооружений» \\ Сибирский федеральный университет, Россия, Красноярск \\ E-mail: roslyakovamary@mail.ru
}

В статье рассматривается суть и отличительные черты европейской модели организации рынка ипотечных ценных бумаг. Были выделены факторы, сдерживающие рост ипотечного кредитования и ценных бумаг на российском рынке. Приведена сравнительная характеристика рынка ипотечных облигаций стран Европы и России.

Ключевые слова: ипотека, ипотечные облигации, рынок ипотечных ценных бумаг, ипотечное покрытие, ипотечное кредитование.

Стремление передовых стран увеличивать объемы ипотечного кредитования, используя преимущества национальных экономик и валют, в наше время бурного обсуждается экспертным сообществом. Безусловно, важность развития рынка ипотечного кредитования для любого государства неоценима. Желание правительств удовлетворить потребности населения в дешевом и доступном жилье, при этом обеспечить рабочими местами строительную отрасль и предоставить возможность зарабатывать банкам в современных условиях, вполне очевидно. Однако подобные стремления правительств, особенно передовых стран, приводят к серьезным проблемам на финансовых рынках. Необходимость постоянного контроля и финансовой помощи со стороны государства участникам рынка ипотечного кредитования в последнее время приобретает все большие масштабы, в частно- сти, в развитых странах с усовершенствованной ипотечной инфраструктурой.

Стремительный рост ипотечных рынков в странах Европейского Союза (ЕС) можно объяснить несколькими факторами:

1) расширение прав и возможностей на финансовых рынках в ряде стран ЕС;

2) рост строительных объемов и продаж доступного социального жилья;

3) пониженные процентные ставки ипотечного кредитования;

4) рост интереса и доверия со стороны инвесторов к инструментам инвестирования на вторичном ипотечном рынке

5) возможность получения налоговых вычетов по процентным платежам ипотечных займов;

Современные тенденции развития жилищного и строительного рынков в ЕС показывают, 
что многие эмитенты рассматривают облигации с ипотечным покрытием в качестве главного инструмента по привлечению финансирования.

Согласно официальным данным Европейской ипотечной федерации, находящиеся в обращении облигации обеспечены, в большей степени, такими активами, как: ипотечные ссуды и кредиты общественному сектору.

Однако важно отметить, что не во всех странах Европейского союза выпуск ипотечных облигаций рассматривается в качестве главного источника ипотечного финансирования. Так, например, в большинстве государств Западной Европы первичным источником ипотечного жилищного финансирования являются депозиты клиентов, за счет которых банки формируют большую часть своих денежных ресурсов [1].

В таких странах, как Дания, Испания и Великобритания, напротив, ипотечные ценные бумаги имеют больший удельный вес в структуре источников ипотечного финансирования.

Кроме того, Европейская модель организации рынка ипотечных ценных бумаг является одноуровневой. Так, секьюритизация ипотечных кредитов в Европе осуществляется с помощью депозитных или фондовых инструментов без передачи ипотечных кредитов специализированным агентствам, в отличие от США. Инфраструктура рынка ипотечного кредитования в странах ЕС разнообразна. К первичным кредиторам относятся стройсберкассы, ипотечные, кооперативные и универсальные банки.

В 1967 г. была создана Европейская ипотечная федерация (англ.- European Mortgage Federation, EMF), целью которой является объединение ипотечных учреждений стран ЕС для создания единого ипотечного пространства. Анализируя развитие рынка ипотечного кредитования в Европе, можно выделить следующие тенденции:

- усиление интеграционных процессов на национальных рынках стран-членов;

- либерализация (снятие ряда ограничений при выдаче ипотечных кредитов, изменение природы ипотечных институтов, отмена принципа специализации в банках);

- открытость рынков стран ЕС для создания конкурентной среды на общем европейском рынке ипотечного кредитования;

- единая валюта как драйвер роста масштабов рынка ипотечного кредитования в Европе.

Несмотря на усиление интеграционных про- цессов, системы ипотечного кредитования в европейских странах неоднородны ввиду специфики национальных законодательств, особенностей исторического развития и социальноэкономической политики.

Эталоном европейской модели организации рынка ипотечных ценных бумаг (ИЦБ) является система Германии, где возник первый вид ИЦБ в форме закладного листа (phandbriefe), который выпускала Ассоциация землевладельцев в г. Силезии с 1770 года. На современном этапе развития рынок ИЦБ Германии характеризуется тремя видами одноуровневых моделей ипотечного жилищного кредитования (ИЖК).

Что примечательно, значительная часть инвесторов, вложивших свои сбережения в обеспеченные облигации, номинированные в евро, расположена в Европе, и в большей степени именно в Германии.

Итак, в настоящее время в Германии насчитывается порядка 80 банков, осуществляющих выпуск обеспеченных облигаций (в том числе 18 ипотечных банков, 10 земельных банков и примерно 30 сберегательных банков). В целом в Германии все организации, выпускающие ипотечные облигации, можно условно разделить на три категории:

- частные банки, предоставляющие ипотечные кредиты, все услуги кредитования коммунальной сферы и жилья; кроме частных ипотечных банков существуют смешанные финансово-кредитные организации, имеющие возможность предоставлять кредитные услуги универсальных коммерческих банков;

- институты кредитования общественного сектора (земельные банки и.т.д), часто владельцами таких организаций являются региональные сберегательные банки;

- частные корабельные ипотечные банки.

Схема выпуска ипотечных облигаций в Германии, так называемая Pfandbrief (юридический термин): 1) закладная, закладной банковский лист, залоговое свидетельство, ипотечный документ, закладной лист; 2) банковское дело: ипотечная облигация; 3) ценные бумаги: обеспеченная облигация) предполагает, что залоговые активы, предоставленные банку, учитываются на специальных счетах баланса и не могут быть использованы в каких-либо других целях. При этом банк делает выпуск облигаций, которые выступают гарантом для их держателя, в случае если эмитент обанкротиться. 
Выпуск немецких ипотечных облигаций Pfandbrief осуществляется согласно закону о кредитных операциях, а также специальным актом, затрагивающим все аспекты эмиссии, обращения и погашения ипотечных облигаций. Главная цель данного регулирующего акта состоит в том, чтобы защитить интересы инвесторов. В действительности, в случае если банк, являющийся эмитентом ипотечных облигаций Pfandbrief, становится неплатежеспособным, то держатели этих облигаций имеют приоритетное право требования исполнения обязательств по этим облигациям за счет ипотечного обеспечения [1].

Рассмотрим некоторые особенности данного вида ипотечных ценных бумаг.

Немецкие ипотечные облигации имеют традиционную структуру денежных потоков: фиксированная сумма основного долга выплачивается по окончании срока обязательств эмитента, фиксированные проценты выплачиваются в сроки, определенные условиями выпуска. С правовой точки зрения немецкие ипотечные облигации - это обеспеченные облигации, удостоверяющие следующие права их владельцев:

1) на получение от эмитента их номинальной стоимости в предусмотренные сроки;

2) на получение от эмитента установленных процентов;

3) преимущество перед другими кредиторами эмитента при получении возмещения (в случае неисполнения эмитентом принятых на себя обязательств) при реализации активов, включенных в состав обеспечения ипотечных облигаций.

Немецкие ипотечные облигации Pfandbrief выпускаются кредитными институтами, которые имеют лицензию на осуществление деятельности по выпуску Pfandbrief. Так, например, для того чтобы получить подобную лицензию, банк должен обладать капиталом в размере не менее 25 млн. евро.

Далее рассмотрим российский рынок ИЦБ. Для России важной задачей является развитие механизмов ипотеки и ипотечного кредитования. Это позволило бы решить ряд социальных, экономических и финансовых проблем. Ипотечное кредитование не способно развиваться без рынка ИЦБ. В секьюритизации ипотечных кредитов кроется реальная возможность снижения рисков ипотечного кредитования [2].

В 2016 году в нашей стране была введена
«Фабрика ипотечных ценных бумаг» («Фабрика ИЦБ») - программа, выступающая в качестве ипотечного агента, который обеспечивает финансирование и рефинансирование ипотечных кредитов через выпуск облигаций с ипотечных покрытием. Внедрение этой программы обеспечило рост российского рынка ИЦБ.

Среди преимуществ «Фабрика ИЦБ» можно выделить льготное налогообложение, уменьшенная нагрузка на капитал и увеличенная доходность по сравнению с ОФЗ (облигации федерального займа). Не смотря, на указанные выше характеристики стабильный интерес инвесторов к данным бумагам не подтверждается. Вследствие этого нельзя гарантировать то, что сегмент рынка может работать самостоятельно без дополнительного стимулирования [3].

Так, например, для поддержания внимания потенциальных инвесторов ВТБ принял дополнительные меры. Суть базовых условий «Фабрики ИЦБ» заключается в выплате купонного дохода, который зависит от множества факторов, в числе которых доходность портфеля с учетом ставки рефинансирования и досрочной выплаты ипотечных кредитов, что представляет меньший риск для инвесторов. Интерес к облигациям, в частности к ипотечным, банки повышают за счет введения выплат не в конце срока погашения, а малыми долями на всем сроке владения бумагами. В своею очередь, ВТБ принял решение об использовании процентного свопа, который позволяет фиксировать выплаты по купонам, что увеличило интерес у потенциальных инвесторов за счет того, что появилась возможность реинвестировать, полученный от владения ценной бумагой, доход.

Главным фактором, сдерживающим развитие ипотечного кредитования и ценных бумаг, остается отсутствие на финансовом рынке долгосрочных дешевых ресурсов, которые можно было бы направить в сектор жилищного кредитования [4].

На данный момент ипотечным агентом в нашей стране является «ДОМ.РФ» (ранее «Ипотечный агент «Фабрика ИЦБ»»). По данным «Дом. рф» основными инвесторами в ИЦБ в Российской Федерации являются банки и НПФ. Доля физических лиц на сегодняшний день очень мала и составляет $1 \%$, банков - $84 \%$, НПФ - 9\%, Дом.рф - 3\%, страховые компании - $2 \%$, УК(ПИФ) - 1\%, прочие - 1\% [6].

В период с января по июль 2020 года в РФ 
было реализовано 4 выпуска ипотечных облигаций на общую сумму 31,1 млрд. рублей. На момент 30.06.2020 года в обращении находились 129 выпусков ипотечных облигаций на сумму 494,1 млрд. руб., из которых 81\% доля ИЦБ ДОМ. РФ.

Показатели рынка ипотечных облигаций в 2020 году оказались следующими:

- На момент окончания июня 2020 процент доходности ипотечных облигаций составил 6\%;

- Из-за нестабильности экономической ситуации на фоне пандемии в первом полугодии 2020 наблюдалась незначительная активность торгов ипотечных облигаций, в мае-июне состояние рынка начало стабилизироваться;

В целом на российском рынке ипотечных облигаций на сегодняшний день прослеживается положительная динамика. Однако, анализируя график (рисунок 1), можно сделать вывод о том, что процент доходности 6\% является непривлекательным для инвесторов, для которых более стабильным и менее рискованным инструментом инвестирования является ОФЗ [5].

Одними из главных «потребителей» ипотечных бумаг являются управляющие компании, в которых располагаются фондовые пенсионные средства, а также финансово-кредитные организации. Часть инвесторов в данном сегменте пока что незначительна, но несмотря на это возможность приобрести ипотечные облигации есть у каждого.

Частные инвестора не спешат вкладывать свои средства в ипотечные облигации из-за меньшего процента дохода в сравнении с другими инструментами и более сложного анализа данного инвестиционного инструмента. Даже для профессионального участника облигационного рынка задача проанализировать доходность по ипотечным ценным бумагам пред- ставляется сложной. Кроме этого, инвесторов «отпугивает» продолжительность срока погашения ипотечных облигаций. В сравнении, погашение облигаций федерального займа может составлять от 1 года, а срок выплаты ипотечных облигаций достигает десятки лет [6].

Кроме этого, на низкий спрос ипотечных облигаций в нашей стране влияет малое количество ИЦБ, которые находятся в свободном обращении. Чаще всего опытные инвесторы выкупают фиксированное количество ценных бумаг и держат их в своих инвестиционных портфелях до окончания срока погашения. Возможно, для удовлетворения потребности на покупку или продажу облигации брокеру необходимо довольно продолжительное время на организационные вопросы вымещения ценных бумаг на рынок, что не устраивает инвесторов.

Ипотечные сертификаты участия (далее ИСУ) являются альтернативой облигаций с ипотечным покрытием. Самым главным недостатком ипотечных сертификатов участия является их низкая ликвидность и невозможность их включения в Ломбардный список, в то время как облигации с ипотечным покрытием обладают высокой ликвидностью и включены в Ломбардный список ЦБ.

В свою очередь, достоинство ипотечных сертификатов можно считать двухуровневое обеспечение: за счет «подкрепления» реальным активом-недвижимостью, а также данная ценная бумага обеспечена поддержкой Дом.рф, которое является государственной организацией. Дом.рф имеет высокий уровень кредитоспособности по национальной шкале, и на уровне финансовых обязательств Правительства РФ по международной шкале.

Несмотря на то, что ипотечные сертификаты участия являются достаточно интересным ин-

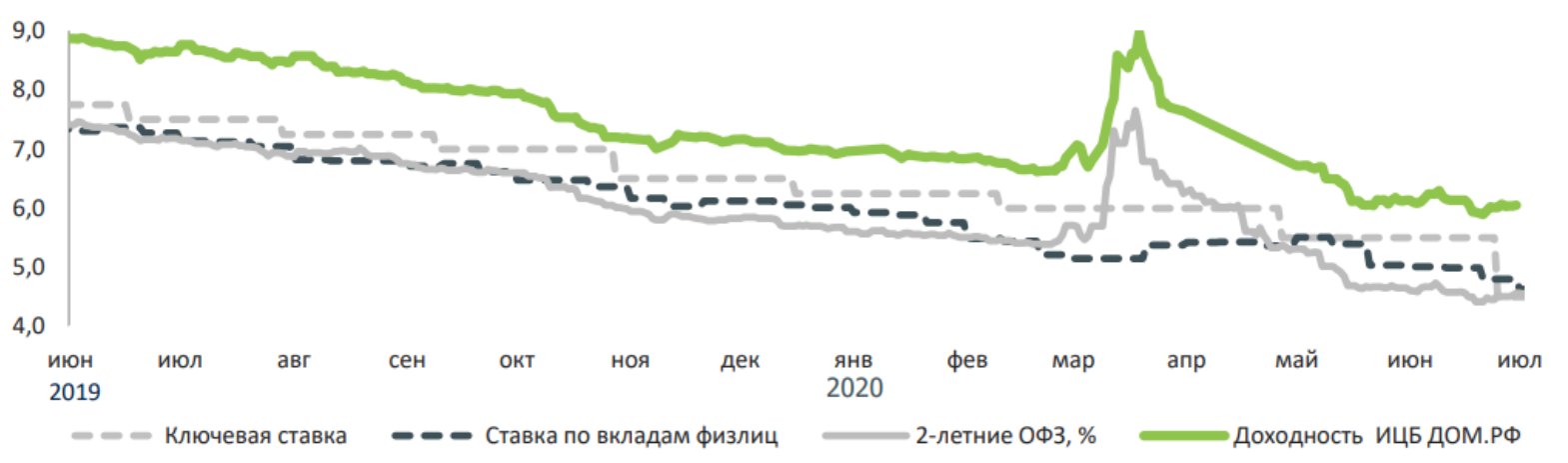

Рисунок 1. Доходность ипотечных облигаций 
струментом и имеют преимущества над облигациями с ипотечным покрытием в виде скорости получения прибыли, размеры прибыли и дешевизны, данный инструмент обладает низкой ликвидностью и более высокими рисками, что сдерживает развитие ипотечных сертификатов участия. Кроме того, Центробанк России ужесточил требования по инвестированию в ИСУ для основного типа инвесторов в данный вид ценных бумаг - негосударственных пенсионных фондов, что повлекло дальнейшее снижение интереса рынка и это отразила цена бумаги.

Одним из недостатков ИСУ является их сложность в оценке. У инвесторов вызывают опасения неопределенные характеристики данного инструмента, связанные с отсутствием фиксированной доходности. Кроме этого, на данный момент рыночная среда не способствует тому, чтобы ИСУ признавали в качестве надежного инвестиционного инструмента. На данный момент ипотечные сертификаты участия не применяется в биржевых сделках, а так же они лишены рыночных стимулов. К примеру, ИСУ, «подкрепленные» поручительством Дом.рф имеют квалификацию в торговых портфелях банков, которые обладают высоким риском, помимо этого, они вычитаются из общего объема капитала (вес которого может достигать 10\%), к тому же они не включены в реестр ликвидных активов и не состоят в ломбардном списке ЦБ России. К недостаткам можно отнести тот факт, что лимит на пополнение пенсионных накоплений в ипотечные облигации составляет 10\%, этот показатель соответствует другим инвестиционным инструментом с соразмерными рисками (структурные продукты, акции вне котировального списка первого уровня, низкорейтинговые облигации).

Ипотечные облигации не привлекают инвесторов не только из-за продолжительного срока выплаты процентов, небольшого дохода и сложности в анализе, но и из-за опасений после ипотечного кризиса 2008 года в Америке. Причиной обвала рынка недвижимости стало резкое увеличение количества невыплат ипотечных займов. Кризис привел не только к краху рынка недвижимости, но и обвалу фондового рынка США. Данный опыт в мировой истории ипотечных ценных бумаг, так же негативно сказывается на спросе данного инструмента и у отечественных инвесторов в нашей стране.

В наше время мировой опыт ипотечного кредитовая у многих вызывает интерес. Регулирование зарубежной концепции ипотечных облигаций на уровне закона представляется невозможным для применения к специфике смешанной экономики нашей страны. В России необходимо разработать системный подход, начиная с создания основополагающих этапов ипотечного жилищного кредитования. Так же нужно подготовить для инвесторов урегулированные прозрачные условия с минимизацией рисков. Следствием этого будет служить повышение эффективности ипотечного кредитования и увеличение притока денег в строительную и банковскую экономику страны.

Таким образом, невзирая на то, что сфера ипотечного кредитования с каждый годом совершенствуется, в частности благодаря государственной поддержке, многие части по-прежнему остаются «сырыми» и требуют доработки. В процессе разработки улучшений системы ипотечного кредитования стоит учитывать опыт зарубежный стран, особенно США, так как на сегодняшний день рынок ИЦБ этой страны является самым развитым в мире. Кризис ипотечных ценных бумаг в США 2008 года указывал какие ошибки могут быть допущены и какие экономические механизмы нужно ввести для развития рынка ипотечного кредитования.

\section{Библиографический список}

1. Данкевич Е.Л. Анализ динамики и особенностей развития ипотечных облигаций в европейском союзе (на примере Германии)/ Е. Л. Данкевич // Труд и социальные отношения. - 2013 - № 11- с. 116-124

2. Широнина Е.M., Чернышев М. А., Меграбян 3. С. Проблемы рынка ипотечных облигаций в россии/ Е. М. Широнина, М.А. Чернышев, 3. С. Меграбян / Экономика и предпринимательство. - 2013 - № 3(32)- с. 146-148

3. Абдулкадыров С.С. Направления развития правового регулирования ипотечных облигаций/ С. С. Абдулкадыров / Вопросы гуманитарных наук. - 2009 - № 3(41)- с. 108-113

4. Как рынок ипотечных ценных бумаг поможет развитию жилищного кредитования [Электронный ресурс] URL https://www.vedomosti.ru/finance/blogs/2019/06/17/804348-ipotechnih-razvitiyu-kreditovaniya (Дата обращения 4.08.2020) 
5. Обзор рынка ипотечных облигаций в первом полугодии - начале июля 2020 года [Электронный ресурс] URL https://xn-90an6b.xn - d1aqf.xn - p1ai/upload/iblock/bf4/bf4cbdb31a1a99b3677f761461cc12c1.pdf (Дата обращения 15.08.2020)

6. Жилищный вопрос. Почему ипотечные облигации не востребованы у частных инвесторов [Электронный ресурс] URL https://www.forbes.ru/finansy-i-investicii/357805-bespoleznye-metry-pochemu-v-rossii-nevostrebovany-ipotechnye-obligacii (Дата обращения 4.08.2020)

7. Ипотечные облигации [Электронный ресурс] URL https://yango.pro/blog/ipotechnye-obligatsii/\#01 (Дата обращения 15.08.2020) 